\title{
Successful Repair of Four Cases of Ebstein's Anomaly with a New Surgical Approach: Valved-Skirt Technique
}

\author{
Mohammad Abbasi Tashnizi, ${ }^{1}$ Aliasghar Moeinipour, ${ }^{2}$ Ahmad Rajaii Khorasani, ${ }^{3}$ Atefeh \\ Ghorbanzadeh, ${ }^{4}$ Nahid Zirak, ${ }^{5}$ and Babak Manafi, ${ }^{6,}$ \\ ${ }^{1}$ Associated Professor, Department of Cardiac Surgery, Faculty of Medicine, Imam Reza Hospital, Mashhad University of Medical Sciences, Mashhad, Iran \\ ${ }^{2}$ Assistant Professor, Department of Cardiac Surgery, Faculty of Medicine, Imam Reza Hospital, Mashhad University of Medical Sciences, Mashhad, Iran \\ ${ }^{3}$ Cardiac Surgeon, Chief of Department of Cardiac Surgery, Razavi Hospital, Mashhad, Iran \\ ${ }^{4}$ Student Research Committee, Faculty of Medicine, Mashhad University of Medical Sciences, Mashhad, Iran \\ ${ }^{5}$ Associated Professor, Department of Anesthesiology, Faculty of Medicine, Imam Reza Hospital, Mashhad University of Medical Sciences, Mashhad, Iran \\ ${ }^{6}$ Assistant Professor of Cardiovascular Surgery, Faculty of Medicine, Hamadan University of Medical Sciences, Hamadan, Iran \\ "Corresponding author: Babak Manafi, Assistant Professor of Cardiovascular Surgery, Faculty of Medicine, Hamadan University of Medical Sciences, Hamadan, Iran. Postal \\ code: 9137913316, Tel/Fax: +98-5138525307, E-mail: manafi@umsha.ac.ir
}

Received 2016 November 12; Revised 2017 January 11; Accepted 2017 February 01

Keywords: Ebstein's Anomaly, Valved-Skirt, Tricuspid Valve Regurgitation

\section{Introduction}

Ebstein's anomaly is a rare congenital heart defect of the tricuspid valve which accounts for less than $1 \%$ of all the congenital heart diseases (1-3). Ebstein malformation is defined as varying degrees of downward displacement of the septal or posterior leaflets or both of the tricuspid valves into the inlet portion of the right ventricle(RV). Also, the anterior leaflet is enlarged and sail-like, but it has a normal position. Thus, the RV is malformed and divided into a proximal thin-walled (atrialized) and a distal thickwalled (ventricularized) $(4,5)$. Atrial Septal Defect (ASD) is the most commonly associated anomaly which presents in $80 \%$ to $94 \%$ of the cases $(3,6)$.

Various surgical techniques have been applied to repair this anomaly which are associated with different results (7). The best surgical treatment for the patients with Ebstein's anomaly remains as a challenging problem. In addition, because of the limited knowledge of the longterm outcome of different surgical techniques, choosing a proper technique to repair Ebstein's anomaly is still controversial.

Da Silva et al. (8) described a technique for the repair of Ebstein's anomaly termed cone reconstruction which was a modification of several previous techniques. The operation involves a longitudinal plication of the atrialized RV and the reconstruction of the tricuspid valve leaflets to the true tricuspid annular and restoring the tricuspid valve to the true annulus. Although the cone reconstruction technique improved mortality and morbidity with a decreased incidence of reoperation or tricuspid valve replacement, this technique depends on the surgeon's experiences and also regarding to plication of the RV, it can lead to kinking the right coronary artery or an injury to the conduction tissue and dysrhythmia $(9,10)$.

Here, we report four patients with Ebstein's anomaly who underwent a new surgical procedure termed "Valveskirt technique" which includes leaving the atrialized portion of the RV with implanting a home-made Valved-Skirt at the level of the true tricuspid annulus. We found this method effective, feasible, and time-saving with a low incidence of perioperative complications.

\section{Case presentation}

\subsection{Patients' Information}

Four patients with Ebstein's anomaly were admitted, since August 2011 to November 2014, in the department of cardiac surgery at Imam Reza hospital, a general, governmental, educational, and clinical medical center in Mashhad, Iran. All these patients were from Khorasan Razavi province, Iran. There were two men and two women. The age of patients varied from 12 to 52 years with a mean of 33.5 years. Relevant clinical presentation was the indication for surgical treatment.

\subsection{Preoperative Observations}

All patients had progressive dyspnea and the preoperative New York heart association (NYHA) functional class was III in three patients and IV in one patient. Palpitation, cyanosis, and generalized edema were only found in one patient. Chest X-rays of four patients showed a cardiomegaly with a cardiothoracic ratio greater than 0.6 (Figure 1). Trans-Esophageal Echocardiography (TEE) study 
showed severe tricuspid regurgitation (TR) in all the patients, which was associated with ASD in 2 patients. All the patients had type $\mathrm{C}$ of functional anomalies according to Carpentier's classification (11). One patient had a previous cardiac surgery due to ASD closure 15 years before the time of the study. The electrocardiogram demonstrated incomplete right bundle branch block (IRBBB) in one patient, atrial fibrillation in two patients, and normal sinus rhythm in one other patient.

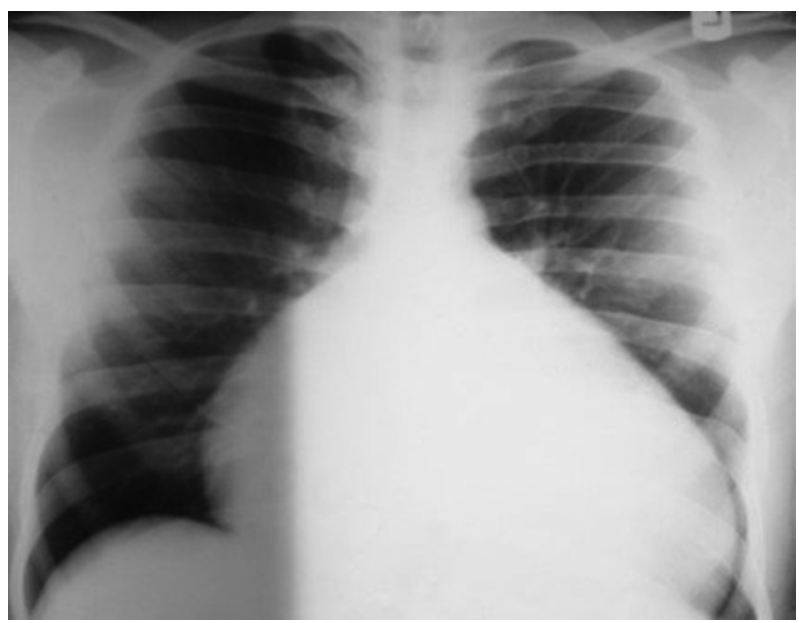

Figure 1. Preoperative Chest Radiography Demonstrated Severe Cardiomegaly

\subsection{Operative Technique}

The operation was performed through median sternotomy. After the administration of heparin, standard cardiopulmonary bypass ( $\mathrm{CPB}$ ) was established with an aortic and bicaval cannulation under normothermic conditions. In two patients who had ASD, the aorta was cross-clamped and the cardioplegia was administered through the aortic root. In the two other patients with intact atrial septum, the heart was perfused and the operation was carried out with their hearts beating. A piece of the pericardium existed for later use as a patch. Tricuspid valve was exposed through an oblique right atriotomy. The severity of the disease and tricuspid valve dysfunction were evaluated to choose a suitable prosthesis valve. Then, the GoreTex patch was secured around the circumference of a prosthetic valve with polypropylene continuous suture (Figure 2). A St. Jude valve (St. Jude Medical, St. Paul, Minnesota) was used in two patients and Hancock Bio-prosthetic valve was used in the two other patients.

After ASD closure by means of pericardial patch (in two patients), the prepared composite prosthesis was inserted in the true tricuspid annulus, above the functional annulus. This implantation was secured by a continuous $3-0$ suture. Finally, the valve-skirt technique was completed by RA reduction plasty (Figure 3). In this technique, there was no attempt to plicate atrialized portion of the RV. Intraoperative TEE revealed no dysfunction of the tricuspid prosthesis valve when the patients were weaned off CPB.

\subsection{Postoperative Observations}

All the operations were performed in a similar way, using a new technique termed "Valved-Skirt technique", for tricuspid valve reconstruction. There was no operation mortality. The mean duration of $\mathrm{CPB}$ was $60 \pm 25$ minutes (between 33 to 76 minutes) with a mean aortic cross-clamp time of $50 \pm 5$ minutes. The mean duration of the intensive care unit stay and postoperative hospital stay were 3.5 days and 11.25 days, respectively. Postoperative complications were not seen in any patients. Pre-discharge echocardiography showed a moderate enlargement of the right atrium and ventricle with a good function of the RV. As well, it was revealed that prosthesis tricuspid valve had a good function in all patients with mean maximum pressure gradient between the $\mathrm{RV}$ and right atrium $3.6 \mathrm{mmHg}$, also TR disappeared in two patients and was mild in two. Pre-discharge ECG demonstrated normal sinus rhythm in three patients and IRBBB in one patient. All patients were discharged with a good clinical condition. Patient's intraoperative and postoperative characteristics are shown in Table 1. The follow-up was obtained in three patients with telephone interviews and their recent clinical conditions were recorded. The mean duration of the follow-up was 40 months ranging from 24 to 61 months. One patient was not available. At the time of the follow-up, three of patients were in NYHA class I.

\section{Discussion}

Ebstein's anomaly is a complex congenital defect which was first described by Wilhelm Ebstein in 1866. The main morphological disorder in Ebstein's anomaly is in the tricuspid valve apparatus which consists of the downward displacement of the septal and posterior leaflets (1-3). TR is more common than tricuspid stenosis and it ranges from mild to severe regurgitation and when TR is severe, it can lead to the enlargement of RA and RV (3).

This anomaly has a wide spectrum of the severity of the clinical symptoms. Common clinical presentations are cyanosis, fatigue, dyspnea, palpitations, sudden cardiac death, and other symptoms of right heart failure such as edema and ascites $(4,12)$. However, many patients with a mild form of Ebstein's anomaly remain asymptomatic until later in life (13). Medical management is advised for asymptomatic patients (5). Surgical intervention is recommended in patients with symptoms of TR or progressive 

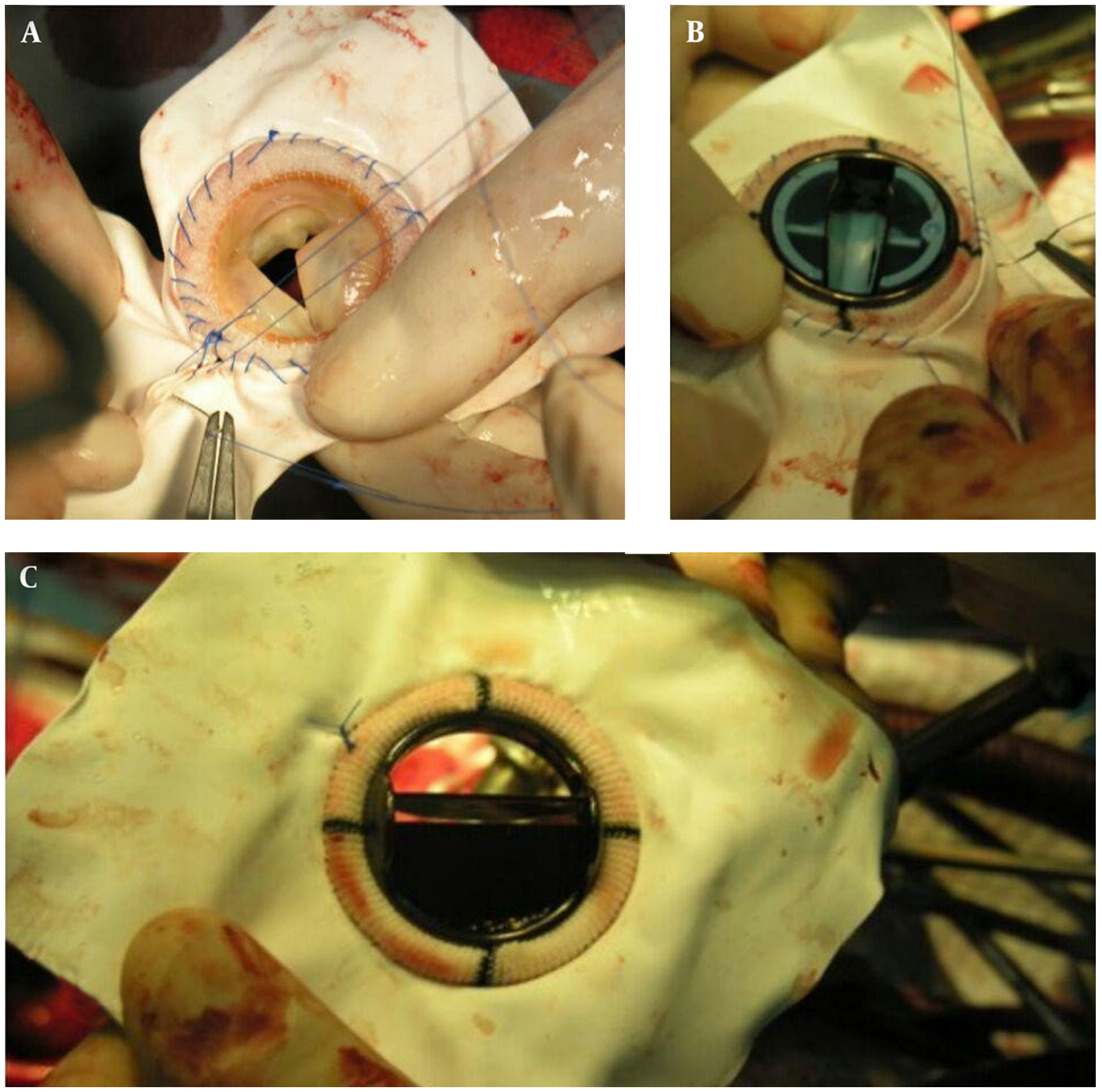

Figure 2. Home-Made Valved-Skirt; Saint-Jude Bi-Leaflet 33 mm Valve Prosthesis (B, C) and Hancock Biologic Valve 27 mm (A) Were Sown in Central of the GORE-TEX Patch

Table 1. Intraoperative and Postoperative Characteristics of the Patients

\begin{tabular}{|c|c|c|c|c|c|c|c|}
\hline No. & $\mathrm{CBP}, \mathrm{min}$ & Cross clamp, min & Implanted Valve & ICU, day & Hospital, day & Rhythm & Follow-up, mo \\
\hline $\mathbf{1}$ & 60 & 35 & St. Jude bileaflet valves, $33 \mathrm{~mm}$ & 3 & 11 & sinus rhythm & not available \\
\hline 2 & 33 & - & Hancock, $33 \mathrm{~mm}$ & 4 & 12 & sinus rhythm, IRBBB & alive, 35 \\
\hline 3 & 76 & 66 & St. Jude bileaflet valves, $34 \mathrm{~mm}$ & 3 & 10 & sinus rhythm & alive, 61 \\
\hline 4 & 72 & - & Hancock, $27 \mathrm{~mm}$ & 3 & 12 & sinus rhythm & alive, 24 \\
\hline
\end{tabular}



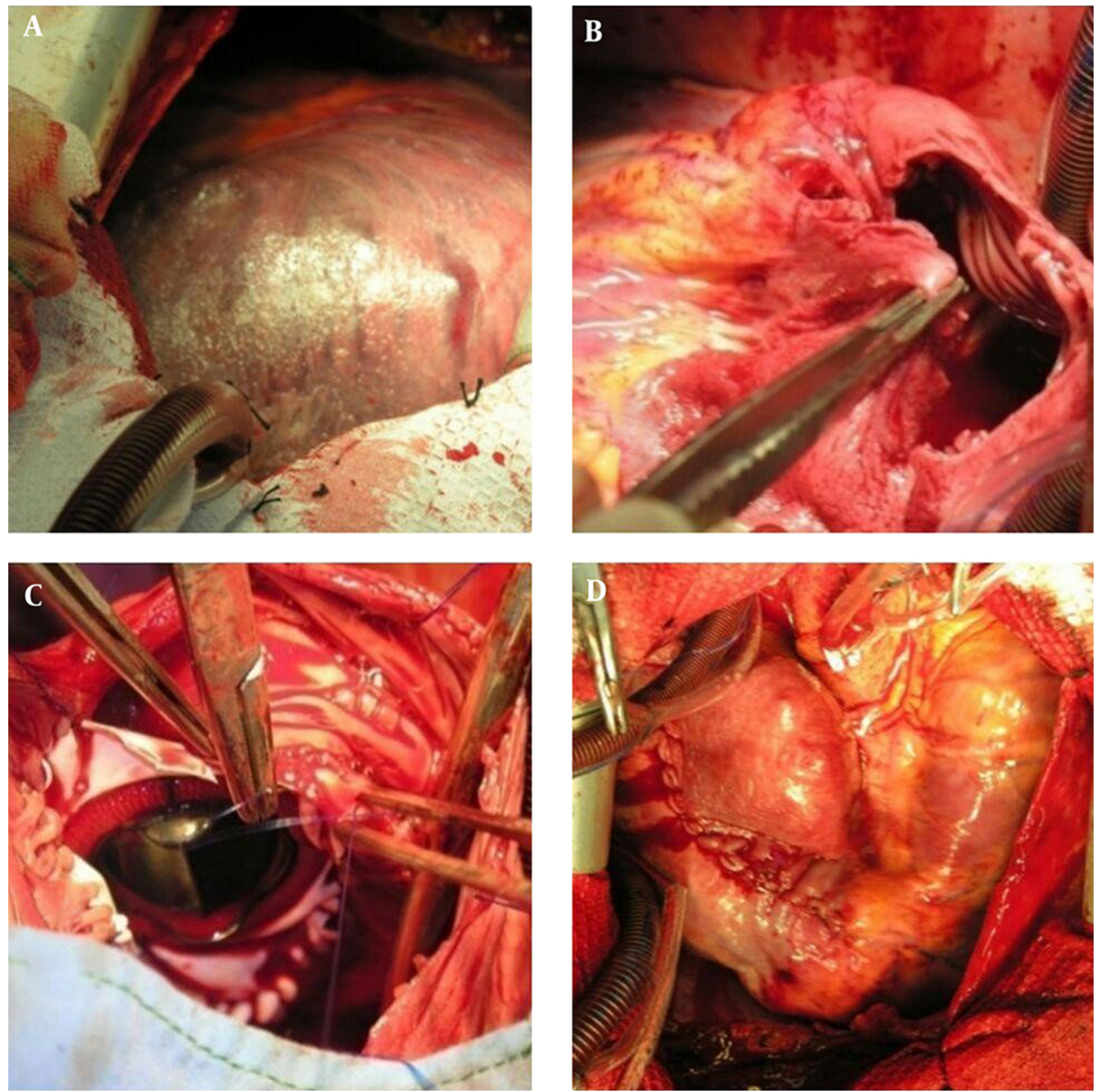

Figure 3. Intraoperative Pictures Of Valved-Skirt Technique for Tricuspid Valve Replacement in Patients with Ebstein's Anomaly. External Appearance of the Dilated Righ Atrium (A). Reduction RA-Plasty (B). Securing the Valved-Skirt at the Anatomical Atrio-Ventricular Junction Without Any Anatomical Changes on Tricuspid Valve Apparatus (C). Final Appearance the Right Atrium After Closing the Free Wall of the Right Atrium (D)

cyanosis (resting oxygen saturation $<90 \%$ ), limited exercise capacity (NYHA III-IV), increasing heart size (cardiothoracic ratio $>65 \%$ ), and embolic event (14). Different surgical techniques have been applied for the repair of Ebstein's anomaly. The feature of the anterior leaflet plays a key role in the decision making regarding the procedure options which consist of tricuspid valve repair or replacement. Displacement and thickening of the anterior leaflet and dense 
attachment to the underlying RV can predict unsuccessful repair of the tricuspid valve in Ebstein's anomaly (7, 9, 10). Carpentier et al. (11) and Danielson et al. (15) described two main techniques for valve repair with plication of the atrialized portion of RV as a surgical treatment of the Ebstein's anomaly. Plication of the atrialized ventricle in Ebstein's anomaly is controversial but seems to be effective because of the enlarged atrialized portion of the RV predisposed to the source of dyskinesia thromboembolic event $(7,16)$. However, some authors reported excellent clinical results in the repair of Ebstein's anomaly by tricuspid valve replacement without plication or the exclusion of the atrialized ventricle (17). The main problems with the surgical treatment for the Ebstein's anomaly are the complication and mortality regarding potential damage to the collateral circulation of the right coronary artery or the conduction pathway system because of the heart block or fatal arrhythmias (18). The prevalence of death related to arrhythmia is relatively high (2). In order to prevent these complications, we designed a new technique in which the RV is not plicate so that it can be prevented from causing damage to the right coronary artery and the conduction pathway system. Also, when the procedure is performed with the on-pump beating heart, any changes in the heart rhythm from cardiac ischemia can be identified.

We successfully performed this technique in 4 patients with Ebstein's anomaly and at the follow-up of 3 patients showed significant improvement in the patients' clinical status. Thus, this surgical technique for Ebstein's anomaly can be performed with low mortality and morbidity. In conclusion, this technique is very simple, efficient, and feasible and every surgeon can learn it. Also, this technique does not change the native anatomy of the valve, so it can better preserve the RV function.

\section{References}

1. Perloff JK, Marelli A. Clinical recognition of congenital heart disease. Elsevier Health Sciences; 2012.

2. Dearani JA, Danielson GK. Congenital Heart Surgery Nomenclature and Database Project: Ebstein's anomaly and tricuspid valve disease. Ann Thorac Surg. 2000;69(4 Suppl):S106-17. doi: 10.1016/S00034975(99)01265-5. [PubMed: 10798422].

3. Kouchoukos NT, Blackstone EH, Hanley FL, Kirklin JK. Kirklin/BarrattBoyes cardiac surgery, expert consult-online and print (2-volume set), 4: Kirklin/Barratt-Boyes cardiac surgery. Elsevier Health Sciences; 2012.
4. Morray B, editor. Preoperative physiology, imaging, and management of Ebstein's anomaly of the tricuspid valve. Seminars in cardiothoracic and vascular anesthesia. 2016; SAGE Publications Sage CA: Los Angeles, CA; pp. 74-81.

5. Galea J, Ellul S, Schembri A, Schembri-Wismayer P, Calleja-Agius J. Ebstein anomaly: a review. Neonatal Netw. 2014;33(5):268-74. doi: 10.1891/0730-0832.33.5.268. [PubMed: 25161135].

6. Attenhofer Jost CH, Connolly HM, Dearani JA, Edwards WD, Danielson GK. Ebstein's anomaly. Circulation. 2007;115(2):277-85. doi:10.1161/CIRCULATIONAHA.106.619338. [PubMed: 17228014].

7. Sarris GE, Giannopoulos NM, Tsoutsinos AJ, Chatzis AK, Kirvassilis G, Brawn WJ, et al. Results of surgery for Ebstein anomaly: a multicenter study from the European Congenital Heart Surgeons Association. J Thorac Cardiovasc Surg. 2006;132(1):50-7. doi: 10.1016/j.jtcvs.2005.10.062. [PubMed: 16798302].

8. da Silva JP, Baumgratz JF, da Fonseca L, Franchi SM, Lopes LM, Tavares $\mathrm{GM}$, et al. The cone reconstruction of the tricuspid valve in Ebstein's anomaly. The operation: early and midterm results. J Thorac Cardiovasc Surg. 2007;133(1):215-23. doi: 10.1016/j.jtcvs.2006.09.018. [PubMed: 17198815].

9. Anderson HN, Dearani JA, Said SM, Norris MD, Pundi KN, Miller AR, et al. Cone reconstruction in children with Ebstein anomaly: the Mayo Clinic experience. Congenit Heart Dis. 2014;9(3):266-71. doi: 10.1111/chd.12155. [PubMed: 24373319].

10. Dearani JA, Bacha E, da Silva JP. Cone reconstruction of the tricuspid valve for Ebstein's anomaly: Anatomic repair. Oper Tech Thorac Cardiovasc Surg. 2008;13(2):109-25. doi: 10.1053/j.optechstcvs.2008.03.003.

11. Carpentier A, Chauvaud S, Mace L, Relland J, Mihaileanu S, Marino JP, et al. A new reconstructive operation for Ebstein's anomaly of the tricuspid valve. J Thorac Cardiovasc Surg. 1988;96(1):92-101. [PubMed: 3386297].

12. Negoi RI, Ispas AT, Ghiorghiu I, Filipoiu F, Negoi I, Hostiuc M, et al. Complex Ebstein's malformation: defining preoperative cardiac anatomy and function. J Card Surg. 2013;28(1):70-81. doi: 10.1111/jocs.12032. [PubMed: 23330581].

13. Luu Q, Choudhary P, Jackson D, Canniffe C, McGuire M, Chard R, et al. Ebstein's anomaly in those surviving to adult life - a single centre experience. Heart Lung Circ. 2015;24(10):996-1001. doi: 10.1016/j.hlc.2015.03.016. [PubMed: 25911143].

14. Krieger EV, Valente AM. Diagnosis and management of ebstein anomaly of the tricuspid valve. Curr Treat Options Cardiovasc Med. 2012;14(6):594-607. doi: 10.1007/s11936-012-0209-2. [PubMed: 23001420].

15. Danielson GK, Fuster V. Surgical repair of Ebstein's anomaly. Ann Surg. 1982;196(4):499-504. doi: 10.1097/00000658-198210000-00014. [PubMed: 7125736].

16. Liu J, Qiu L, Zhu Z, Chen H, Hong H. Cone reconstruction of the tricuspid valve in Ebstein anomaly with or without one and a half ventricle repair. J Thorac Cardiovasc Surg. 2011;141(5):1178-83. doi: 10.1016/j.jtcvs.2011.01.015. [PubMed: 21320712].

17. Hetzer R, Nagdyman N, Ewert P, Weng YG, Alexi-Meskhisvili V, Berger $\mathrm{F}$, et al. A modified repair technique for tricuspid incompetence in Ebstein's anomaly. J Thorac Cardiovasc Surg. 1998;115(4):857-68. doi: 10.1016/S0022-5223(98)70367-8. [PubMed: 9576222].

18. Chauvaud S, Berrebi A, d'Attellis N, Mousseaux E, Hernigou A, Carpentier A. Ebstein's anomaly: repair based on functional analysis. Eur J Cardiothorac Surg. 2003;23(4):525-31. doi: 10.1016/S10107940(02)00836-9. [PubMed: 12694771]. 